\title{
Hsa_circ_0005729 enhances accuracy in diagnosing parathyroid carcinoma
}

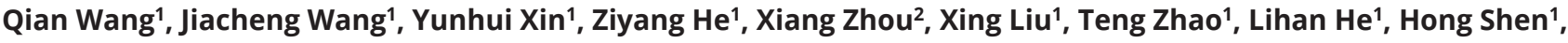 \\ Mulan Jin ${ }^{2}$ and Bojun Wei 1
}

'Department of Thyroid and Neck Surgery, Beijing Chaoyang Hospital, Capital Medical University, Beijing, China

2Department of Pathology, Beijing Chaoyang Hospital, Capital Medical University, Beijing, China

\begin{abstract}
Background: Parathyroid carcinoma (PC), often misdiagnosed as a parathyroid adenoma $(\mathrm{PA})$, is prone to local relapse due to the initial surgery being restricted to parathyroid lesions instead of en bloc resection of parathyroid lesions with negative incision margins. However, it is very challenging to distinguish PC from PA preoperatively; hence, this study investigated an effective biomarker for increasing accuracy in PC diagnosis. Method: First, the differentially expressed circular RNAs between three PC tissues and three PA tissues were screened by high-throughput circular RNA sequencing, and the expression of $h s a_{-}$circ_0005729 was verified by qRT-PCR in 14 patients with PC and 40 patients with PA. Secondly, the receiver operating characteristic curve and the area under the curve (AUC) were used to analyze the diagnostic efficiency of hsa_circ_0005729 in PC by combining with laboratory data. Thirdly, RNF138 mRNA, the corresponding linear transcript of $h s a_{-}$circ_0005729, was measured, and the relationship between $h s a_{-}$ circ_0005729 and RNF138 mRNA was analyzed in patients with PA and patients with PC. Results: Hsa_circ_0005729 expression was significantly higher in patients with PC than in patients with PA. Serum calcium ( $P=0.045)$, alkaline phosphatase (ALP) $(P=0.048)$, and creatinine levels $(P=0.036$ ) were significantly higher in patients with $\mathrm{PC}$ than in patients with PA. The AUC increased to 0.86 when hsa_circ_0005729 combined with serum calcium, creatinine, and ALP. In addition, hsa_circ_0005729 was positively correlated with RNF138 mRNA in patients with PA but not in patients with PC.

Conclusion: The novel circular RNA hsa_circ_0005729 was found to have a higher expression in patients with PC, indicating its usefulness for distinguishing PC from PA.
\end{abstract}
Key Words
- parathyroid carcinoma
- parathyroid adenoma
- non-coding RNA
- circular RNA
- Hsa_circ_0005729

\section{Introduction}

Parathyroid carcinoma (PC) is an extremely rare disease, accounting for $0.005 \%$ of all malignancies (1) and representing approximately $1-5 \%$ of primary hyperparathyroidism cases $(2,3)$. It is worth noting that the best approach for curing PC may be the en bloc resection of parathyroid lesions with negative incision margins (1, $4,5)$, since PC is often insensitive to chemotherapy and radiotherapy $(6,7)$. Most patients with PC suffer from lifetime distress due to repeated surgical resections and have poor prognosis; most die of uncontrollable hypercalcemia due to excessive parathyroid hormone (PTH) secretion (5), with 5- and 10-year survival rates between $77-91 \%$ and $49-77 \%$, respectively $(1,5,8,9,10$, $11,12,13,14)$.

Nowadays, it is extremely difficult to distinguish PC from PA preoperatively (15), and patients with the PC and PA often have similar clinical manifestations and laboratory examinations (16). Most patients with PC have https://ec.bioscientifica.com https://doi.org/10.1530/EC-21-0605 (c) 2022 The authors Published by Bioscientifica Ltd
Endocrine Connections (2022) 11, e210605 
higher levels of serum calcium, PTH, and larger tumor size than patients with PA. However, some PC cases had normal serum calcium or PTH levels. It is also difficult to identify benign or malignant parathyroid tumors by contrastenhanced CT scan, cervical ultrasonography, or 99mTcSestamibi scan (17), which may only help with localization of parathyroid lesions. Fine-needle aspiration biopsy of the parathyroid mass is not recommended for parathyroid tumors, because of the risk of needle track implants (4, 10). Even intra-operative frozen section analysis may fail to identify a tumor as PC, because the pathological features of malignant lesions overlap with benign tumors. Unequivocal PC diagnosis must be confirmed via capsular invasion, vascular infiltration, nerve involvement, tumor infiltration of adjacent tissues, and postoperative local relapse or metastasis $(18,19)$.

Cell division cycle 73 (CDC73) germline mutations and loss of parafibromin staining occur in approximately one out of three of the sporadic patients with PC (20, 21), which may assist in diagnosing PC. However, the absence of CDC73 mutations or loss of parafibromin staining cannot exclude PC (22). A recent study revealed that cancer-derived immunoglobulin $\mathrm{G}$ (cancer- $I g G$ ) expression was higher in PC than in PA (23). However, immunohistochemistry was used to detect the cancer- $\operatorname{Ig} G$, which does not apply to the preoperative diagnosis PC.

Circular RNAs have recently been detectable noninvasively in peripheral blood specimens in several cancers, such as breast cancer and colorectal carcinoma $(24,25,26)$. Upregulated circular RNAs may help to identify an effective diagnostic biomarker for PC. To date, to our knowledge, only one study has described differentially expressed circular RNAs between patients with PC and patients with PA, including hsa_circRNA_0035563, hsa_circRNA_0017545, hsa_ circRNA_0001687, and hsa_circRNA_0075005 (27). However, the global incidence of PC is extremely low, and more $\mathrm{PC}$ cases are required for identifying effective PC biomarkers. This study identified a novel circular RNA hsa_circ_0005729 that may enhance diagnosing PC.

\section{Materials and methods}

\section{Human tissue specimens}

All tissue samples were collected immediately from the patients after resection, snap-frozen in liquid nitrogen, and transferred to $\mathrm{a}-80^{\circ} \mathrm{C}$ refrigerator until RNA extraction, from the Beijing Chaoyang Hospital between October 2017 and September 2020. This study was approved by the Ethics Review Board of Beijing Chaoyang Hospital, Capital Medical University, and all the patients written informed consent was taken.

A total of 14 patients with PC and 40 patients with PA were enrolled, and the clinicopathological characteristics of the cohort are described in Table 1. Two patients were diagnosed PC for the first time in our institution, one was pathologically confirmed with PC based on tumor capsular invasion and the other one based on tumor infiltration of striated muscle and adipose tissues. We collected the two specimens of the primary parathyroid tumors. Other 12 patients with PC were admitted to our institution because of local relapse after 1-6 times operations in other hospitals because of parathyroid tumors. All the 12 patients with

Table 1 Clinicopathological characteristics in patients with pathologically confirmed parathyroid carcinoma (PC) and parathyroid adenoma (PA).

\begin{tabular}{|c|c|c|c|c|}
\hline Characteristics & $\begin{array}{c}\text { Number } \\
(n=54, \%)\end{array}$ & $\begin{array}{c}\mathbf{P C} \\
(n=14, \%)\end{array}$ & $\begin{array}{c}\mathbf{P A} \\
(n=40, \%)\end{array}$ & $\boldsymbol{P}$ \\
\hline \multicolumn{5}{|l|}{ Gender } \\
\hline Female & $35(65)$ & $7(50)$ & $28(70)$ & 0.153 \\
\hline Male & $19(35)$ & $7(50)$ & $12(30)$ & \\
\hline \multicolumn{5}{|l|}{ Age (years) } \\
\hline$<50$ & $29(87)$ & $11(79)$ & $18(45)$ & 0.060 \\
\hline$\geq 50$ & 25 (13) & $3(21)$ & $22(55)$ & \\
\hline \multicolumn{5}{|l|}{ Tumor } \\
\hline Primary & & $2(14)$ & N/A & \\
\hline Recurrence & & $12(86)$ & N/A & \\
\hline \multicolumn{5}{|l|}{ T classification } \\
\hline $\mathrm{T} 1$ & & $1(7)$ & N/A & \\
\hline $\mathrm{T} 2$ & & $9(64)$ & N/A & \\
\hline T3 & & $2(14)$ & N/A & \\
\hline $\mathrm{T} 4$ & & $2(14)$ & N/A & \\
\hline \multicolumn{5}{|l|}{$\mathrm{N}$ classification } \\
\hline NO & & $11(79)$ & N/A & \\
\hline N1 & & $3(21)$ & N/A & \\
\hline \multicolumn{5}{|l|}{ M classification } \\
\hline MO & & $8(57)$ & N/A & \\
\hline M1 & & $6(43)$ & N/A & \\
\hline \multicolumn{5}{|l|}{$\begin{array}{l}\text { TNM stage } \\
\text { (Schulte) }\end{array}$} \\
\hline I & & $5(36)$ & N/A & \\
\hline II & & $0(0)$ & N/A & \\
\hline III & & $3(21)$ & N/A & \\
\hline IV & & $6(43)$ & N/A & \\
\hline
\end{tabular}

N/A, not applicable; TNM staging systems for PC by Schulte: T1, evidence of capsular invasion; $T 2$, invasion of surrounding soft tissues excluding the vital organs trachea, larynx, and esophagus; T3, evidence of vascular invasion; T4, invasion of vital organs, i.e. hypopharynx, trachea, esophagus, larynx, recurrent laryngeal nerve, carotid artery. NO, no regional lymph node metastases; $\mathrm{N} 1$, regional lymph node metastases; $\mathrm{M0}$, no evidence of distant metastases; M1, evidence of distant metastases; I, T1 or T2NOM0; II, T3NOM0; III, any T, N1M0, or T4; IV, any N, M1. 
PC underwent an extended en bloc resection in our institution (28), and we collected 12 specimens of the cervical tumor recurrence. The detailed information of the 14 patients with PC is shown in Table 2.

A total of 6 patients with PC had distant metastases, including the 4 cases with lung metastases, 1 with bone metastases, and 1 with liver and lung metastases simultaneously. We collected 59 tissue samples from the $14 \mathrm{PA}$ and 40 PC patients, including 5 matched distant metastases, with 4 lung metastases and 1 liver metastases. All tissue samples were confirmed with PC pathologically according to the criteria of the WHO Classification of Tumors of Endocrine Organs, 4th Edition, Volume 10 (29).

None of the recruited patients had any other type of cancer or had previously undergone chemotherapy, radiotherapy, or targeted therapy. Patients with multiple endocrine neoplasms, secondary hyperparathyroidism, tertiary hyperparathyroidism, or hyperparathyroidism-jaw tumor syndrome were also excluded according to familial medical histories, preoperative physical examination, laboratory studies, and imaging examinations, such as serum calcitonin, prolactin, insulin, cortisol, aldosterone, brain MRI, abdominal ultrasound, or abdominal contrastenhanced CT.

\section{RNA extraction and RNA quality estimation}

First, three tissue samples from three patients with PC and three tissue specimens from three patients with PA were used for high-throughput circular RNA sequencing. All three patients with PC underwent their first operation in other institutions and were pathologically diagnosed with PC before visiting our institution. They were diagnosed with PC pathologically in our institution due to cervical relapses and distant metastases. One patient had lung metastases, one had bone metastases, and another had lung and liver metastases simultaneously. All tumor tissue samples used for high-throughput circular RNA sequencing were from the cervical relapse cases.

All the fresh-frozen tissues were ground using a tissue homogenizer. rRNA was removed by using an Epicenter Ribo-zero $^{\mathrm{TM}}$ rRNA Removal Kit (Epicenter, Madison, WI, USA) and further treated with RNase R (Epicenter). The total RNA from each tissue specimen was isolated by RNA extraction using TRIzol (Invitrogen) according to the manufacturer's recommendations. The concentration and purity of RNA were evaluated by a Nanodrop 2000 (Wilmington, DE, USA), and RNA integrity was assessed by native agarose gel electrophoresis by inspecting the $28 \mathrm{~S}$ and $18 S$ rRNA bands.

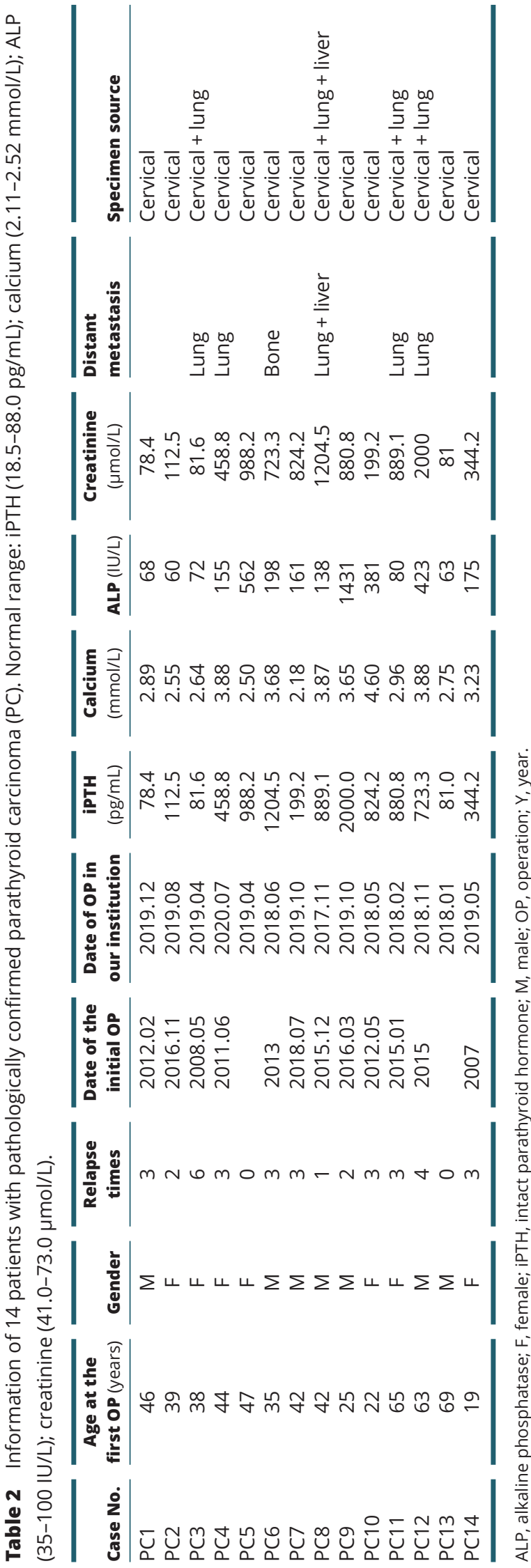




\section{High-throughput circular RNA sequencing}

After removal of rRNA and treatment with RNase R, six RNAs from three PC and three PA tissue samples were prepared for a high-throughput circular RNA sequencing with Illumina sequencing technology from Novegene Inc. Briefly, mRNA was purified from the total RNA using poly-T oligo-attached magnetic beads. First-strand cDNA was synthesized using random hexamer primers and M-MuLV reverse transcriptase; second-strand cDNA synthesis was performed using DNA polymerase I and RNase H. PCR was performed with Phusion High-Fidelity DNA polymerase, universal PCR primers, and index (X) primer. The PCR products were purified, and the library quality was assessed on an Agilent Bioanalyzer 2100 system. The index-coded samples were clustered, and the library preparations were sequenced on an Illumina HiSeq platform, generating $125 \mathrm{bp} / 150 \mathrm{bp}$ paired-end reads. The detailed methods are described in Supplementary Method 1 (see section on supplementary materials given at the end of this article).

\section{Data analysis of the high-throughput circular RNA sequencing}

Clean data (clean reads) were obtained by removing reads containing adapters and poly-N and those of poor quality from the raw data. At the same time, the $\mathrm{Q}_{20}, \mathrm{Q}_{30}$, and $\mathrm{GC}$ contents of the clean data were calculated. All downstream analyseswerebased on high-qualitycleandata. Theexpected number of fragments per $\mathrm{kb}$ of the transcript sequence per million base pairs sequenced (FPKM) is currently the most used method for estimating gene expression levels. The number of FPKM of each gene was calculated based on the length of the gene and the read count mapped to this gene. Genes with an adjusted $P$-value less $<0.05$ were considered as differentially expressed. A corrected $P$-value of 0.005 and $\log 2$ (fold change, FC) of one were set as the thresholds for a significantly differential expression. The detailed data analysis of the high-throughput circular RNA sequencing is described in the Supplementary Method 2.

\section{Quantitative real-time PCR (qRT-PCR) validation}

The primers for the circular RNAs were designed according to the Oligo 7 primer analysis software, and the human $\beta$-actin $(A C T B)$ served as the endogenous control. The details of the primer sequences are shown in Supplementary Table 1. Total RNAs were isolated from fresh-frozen tissues, and the mRNAs were used for the synthesis of cDNAs after removing rRNAs and treatment with RNase R. The PCR was implemented to determine the primer specificity of circular RNA novel_circ_0024633, hsa_circ_0027093, hsa_circ_0005729, novel_circ_0026113, novel_circ_0026101, which are the top five upregulated circular RNAs according to the results of high-throughput circular RNA sequencing.

The expression levels of hsa_circ_0027093, hsa_circ_0005729, and ACTB were further measured in 14 PC tissues and 40 PA tissues using qRT-PCR. The qRT-PCR assays were performed with PrimeScript RT reagent Kit with gDNA Eraser (TaKaRa Code.DRR047) and SYBR Premix Ex Taq II (Tli RNaseH Plus) (TaKaRa Code.DRR820) in TaKaRa TP600 PCR Thermal Cycler Dice and ABI StepOne RealTime PCR System.

First, cDNAs were synthesized using the PrimeScript RT reagent Kit with a gDNA Eraser. Each reaction consisted of $1.5 \mu \mathrm{g}$ of total RNA, $2 \mu \mathrm{L}$ of $5 \times$ gDNA eraser buffer, $1 \mu \mathrm{L}$ gDNA eraser, and sufficient RNase-free $\mathrm{dH}_{2} \mathrm{O}$ to reach a total volume of $10 \mu \mathrm{L}$ and was performed at $42^{\circ} \mathrm{C}$ for 2 min. Secondly, RT products were synthesized by using SYBR Premix Ex Taq II (Tli RNaseH Plus). Each reaction consisted of $10 \mu \mathrm{L}$ of cDNA, $4 \mu \mathrm{L}$ of $5 \times$ PrimerScript Buffer 2 (for real-time), $1 \mu \mathrm{L}$ of PrimeScript RT Enzyme Mix I, $1 \mu \mathrm{L}$ of RT Primer mix, and $4 \mu \mathrm{L}$ of RNase-free $\mathrm{dH}_{2} \mathrm{O}$ and was performed at a temperature of $37^{\circ} \mathrm{C}$ for $15 \mathrm{~s}$ and then $85^{\circ} \mathrm{C}$ for $5 \mathrm{~s}$. The PCR products were further synthesized with $2 \mu \mathrm{L}$ of the RT products, $10 \mu \mathrm{L}$ of SYBR Premix Ex Taq II $(2 \times), 1 \mu \mathrm{L}$ of forward primer $(10 \mu \mathrm{M}), 1 \mu \mathrm{L}$ of reverse primer (10 Mm), and $6 \mu \mathrm{L}$ of RNase-free $\mathrm{dH}_{2} \mathrm{O}$ at $95^{\circ} \mathrm{C}$ for $30 \mathrm{~s}$, followed by the 40 cycles of $95^{\circ} \mathrm{C}$ for $5 \mathrm{~s}$ and then $60^{\circ} \mathrm{C}$ for $30 \mathrm{~s}$. All the reactions were performed in triplicate.

The expression levels of the circular RNAs were calculated using the $\Delta \mathrm{CT}$ method as follows: expression $_{\text {hsa_circ_0005729 }}=-\Delta \mathrm{CT}=-\left(\mathrm{CT}_{\text {hsa_circ_0005729 }}-\right.$ $\left.\mathrm{CT}_{\text {AСTB }}\right)$, expression hsa_cir__0027093 $=-\Delta \mathrm{CT}=$ $-\left(\mathrm{CT}_{\text {hsa_circ_0027093 }}-\mathrm{CT}_{A C T B}\right)$, and expression ${ }_{R N F 138 \mathrm{mRNA}}=$ $-\Delta \mathrm{CT}=-\left(\mathrm{CT}_{R N F 138 \mathrm{mRNA}}-\mathrm{CT}_{A C T B}\right)$.

\section{Clinical, laboratory data collection, and analysis}

Clinicopathological features and laboratory data of 14 PC and 40 patients with PA were collected and analyzed. Information was collected including age, sex, serum calcium, calcium on the first postoperative day, the decline in calcium levels (calcium on the first postoperative day relative to preoperative), serum intact PTH (iPTH), iPTH on the first postoperative day, the decline in the iPTH (iPTH on the first postoperative day relative to https://ec.bioscientifica.com https://doi.org/10.1530/EC-21-0605 (c) 2022 The authors Published by Bioscientifica Ltd
This work is licensed under a Creative Commons Attribution-NonCommercial-NoDerivatives 4.0 Internationab dicense:ifica.com at 04/26/2023 01:23:31AM 
preoperative), phosphorus, alkaline phosphatase (ALP), creatinine, 25-hydroxy vitamin D, 24-h urinary calcium, relapse times, the date of the initial operation, date of the operation in our institution, and sites of the distant metastases. We analyzed the differences of the above clinical parameters between 14 PC and 40 patients with PA. We also examined the above indexes between 8 patients with PC without the distant metastases and 6 PC cases with the metastases. The factors with the significant differences between patients with PC and patients with PA were further analyzed together with hsa_circ_0005729 and hsa_circ_0027093.

\section{ROC curves and AUC analysis of laboratory parameters were used to assess the diagnostic efficiency of PC}

Laboratory parameters that were significantly different between the patients with PC and patients with PA were further used to assess the diagnostic power of PC by these parameters alone and combined with hsa_circ_0027093 and hsa_circ_0005729 (30) according to the logistic regression, ROC curve analysis, and the AUC calculation. The cutoff values were identified according to the Euclidean index (31), along with the sensitivity, specificity, and 95\% CIs.

\section{Analysis of the correlation between hsa_circ_0005729 and RNF138 mRNA in PC and patients with PA}

RNF138 is the host gene of hsa_circ_0005729, and we measured the expression of RNF 138 mRNA by qRT-PCR in 14 patients with $\mathrm{PC}$ and 40 patients with PA. The relationship between the hsa_circ_0005729 and RNF138 mRNA in 54 patients was analyzed by a Pearson's correlation analysis. In addition, the relationship between the hsa_circ_0005729 and RNF138 mRNA in 14 PC and 40 patients with PA were analyzed, respectively.

\section{Statistical analysis}

Statistical analyses were performed with SPSS version 23.0, GraphPad Prism 8.0, and SigmaPlot 14.0 (Systat Software Inc, Beijing, China). All the measurements were repeated three times in triplicate. Differences in hsa_circ_0027093, hsa_circ_0005729, RNF138 mRNA, and laboratory parameters between patients with PC and patients with PA were determined using the Mann-Whitney $U$-test. The clinicopathological features of different groups were evaluated using chi-square tests. Logistic regression,
ROC curve, and AUC calculation were performed to assess the diagnostic value of serum calcium, ALP, creatinine, hsa_circ_0027093, and hsa_circ_0005729 alone, or a combination of them in PC. $P<0.05$ was considered as statistically significant.

\section{Results}

\section{Clinical characteristic features of PC and patients with PA}

This study included 14 patients with PC and 40 patients with PA. The PC group had an equal number of males and females in our institution (7 vs 7), and the mean age was $42.9 \pm 15.1$ years (median: 42 years, range: $19-69$ years) at the time of initial operation. The PA group had a femaleto-male ratio of 2.3:1 (28 vs 12 ), and the mean age was $49.4 \pm 11.2$ years (median: 52 , range: $28-66$ ). There was no significant difference in either age or the sex distribution between the patients with PC and patients with PA, but the age at the initial operation among the patients with PC was approximately 7 years younger than that among the patients with PA. Shaha et al. (15) and Schulte et al. (32) established different TNM staging systems that differ in the $\mathrm{T}$ classification for identifying PC. The T classification is associated with the tumor size in the Shaha system, while the Schulte system utilizes the histopathological features. The Schulte system was used because most patients with PC in this study had experienced recurrence, and the histopathological features were considered as the better indicators (Table 1).

\section{Overview of the results of the high-throughput circular RNA sequencing}

A total of three PC and three PA tissues were used for screening the differentially expressed circular RNAs by a high-throughput circular RNA sequencing on the Illumina HiSeq 2500 Platform. In total 550,623,586 raw reads were generated, including the $279,097,882$ raw reads for PC tissues and 271,525,704 raw reads for the PA tissues. A total of $524,800,460$ clean reads $(266,092,644$ for PC and $258,707,816$ for PA) were filtered after removing the poor quality, poly-N-containing, and adapter-containing reads from the raw data. Finally, 16,038 circular RNAs were identified as differentially expressed between the PC and PA according to the find_circ software and then used for further analysis. (c) 2022 The authors Published by Bioscientifica Ltd
This work is licensed under a Creative Commons Attribution-NonCommercial-NoDerivatives 4.0 elnternationad dicense ifica. com at 04/26/2023 01:23:31AM 

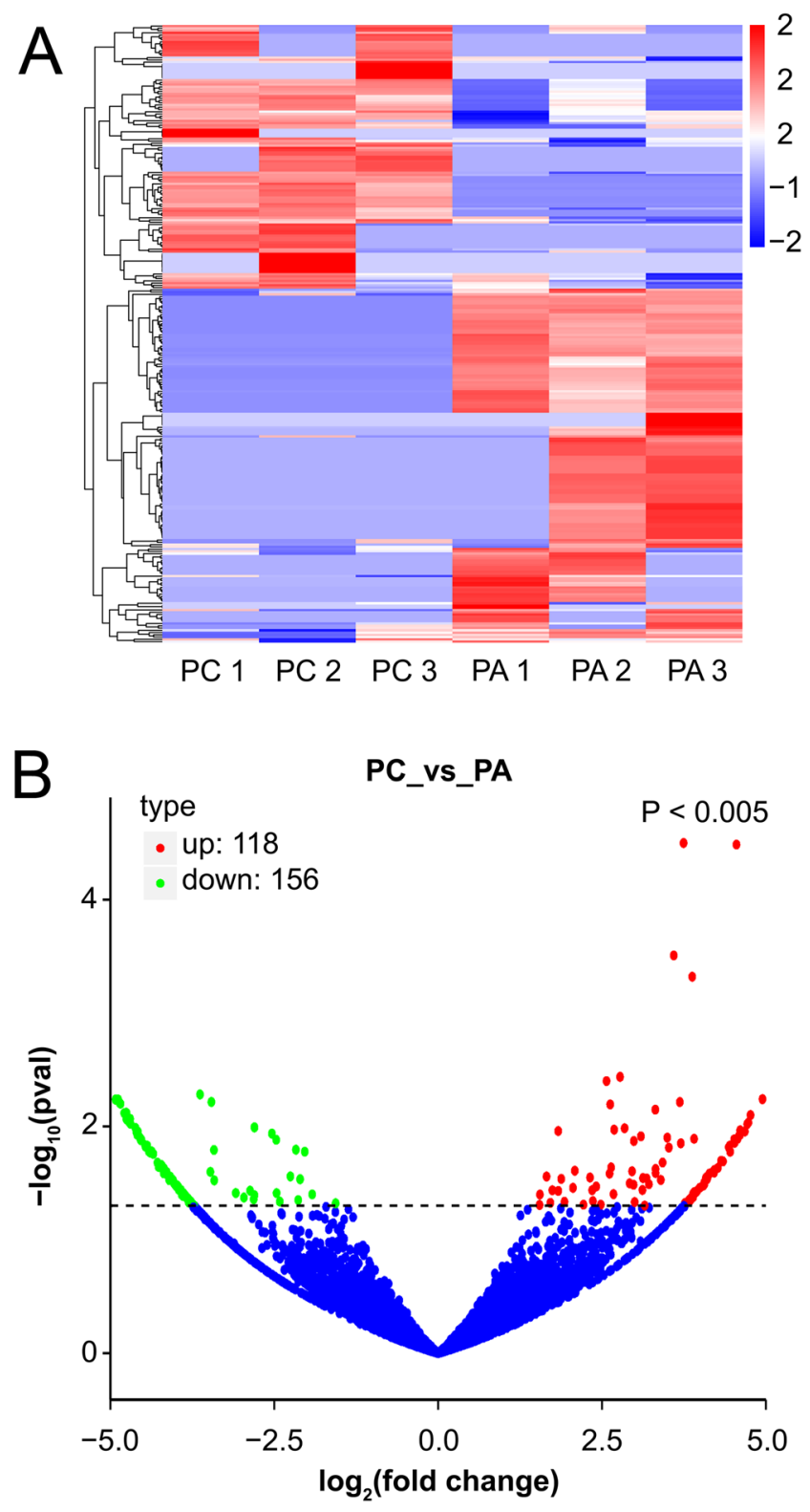

Figure 1

Heat map and volcano plot were constructed to show the differentially expressed circular RNAs between three parathyroid carcinoma (PC) and three parathyroid adenoma (PA) tissues. (A) Heat map: differentially expressed circular RNAs in three PC (PC1+PC2+PC3) and three PA (PA1+PA2+PA3) tissues were screened using high-throughput circular RNA sequencing. Each column represents one specimen, and each row shows one circular RNA. (B) Volcano plot: a total of 274 significant differentially expressed as circular RNAs were identified, including 118 upregulated and 156 downregulated circular RNAs in PC relative to PA, according to the threshold $\log 2(\mathrm{FC})>1$ or $<-1$ and $P<0.005$.

\section{Analysis of differentially expressed circular RNAs PC vs PA}

A total of 274 significant differentially expressed circular RNAs were identified according to the threshold $\log 2$ (FC) greater than 1 or lesser than -1 and corrected $P<0.005$, including 118 upregulated and 156 downregulated circular RNAs in PC relative to PA. Clustering heatmaps and volcano plots were constructed to show the differentially expressed circular RNAs (Fig. 1A and B). The top ten upregulated circular RNAs in PC are shown in the Supplementary Table 2.

\section{Hsa_circ_0005729 and hsa_circ_0027093 were significantly higher in 14 PC than patients with PA}

PCR was performed to assess the expression levels of the top five upregulated circular RNAs in the PC tissues, and only hsa_circ_0027093 and hsa_circ_0005729 were chosen to study further because of the good shape of the PCR amplification curve and the specific melt peak. Furthermore, PCR products were detected by gel electrophoresis, and the sequences of $h s a \_c i r c 0027093$ and $h s a \_c i r c \_0005729$ were also identified by sequencing using gel extraction. qRT-PCR was performed to measure the expression of hsa_circ_0027093 and hsa_circ_0005729 in 14 patients with PC and 40 patients with PA. The results showed that both hsa_circ_0005729 and hsa_circ_0027093 were significantly upregulated in 14 patients with PC specimens compared to the 40 PA tissue specimens, with $P=0.0073$ and $P=0.0359$, respectively (Fig. $2 \mathrm{~A}$ and $\mathrm{B})$.

\section{Hsa_circ_0005729 expression was higher in local relapses than in matched distant metastases of the same PC patients}

There was no significant difference of hsa_circ_0005729 expression between patients with PC with $(n=6)$ and without distant metastases $(n=8)(P=0.2824)$, as well as hsa_circ_0027093 $(P=0.8518)$ (Fig. $2 \mathrm{C}$ and D). In addition, we compared the hsa_circ_0005729 expression between local relapse tissues $(n=4)$ and matched distant metastases specimens $(n=5)$, including the four lung metastases and one liver metastases. The results showed that hsa_circ_0005729 expression was higher in the local relapses than in the matched distant metastases of the same patient $(P=0.0226)$ (Fig. $2 \mathrm{E})$, but there was no significant difference of hsa_circ_0027093 expression between the two groups $(P=0.2764)$ (Fig. 2F).

There were 2 specimens from the first-operated patients with PC and 12 specimens from the multifold-operated patients with PC. Hsa_circ_0005729 and hsa_circ_0027093 between the first-operated and multifold-operated patients with PC were analyzed, and the results showed no significant differences in the hsa_circ_0005729 and 

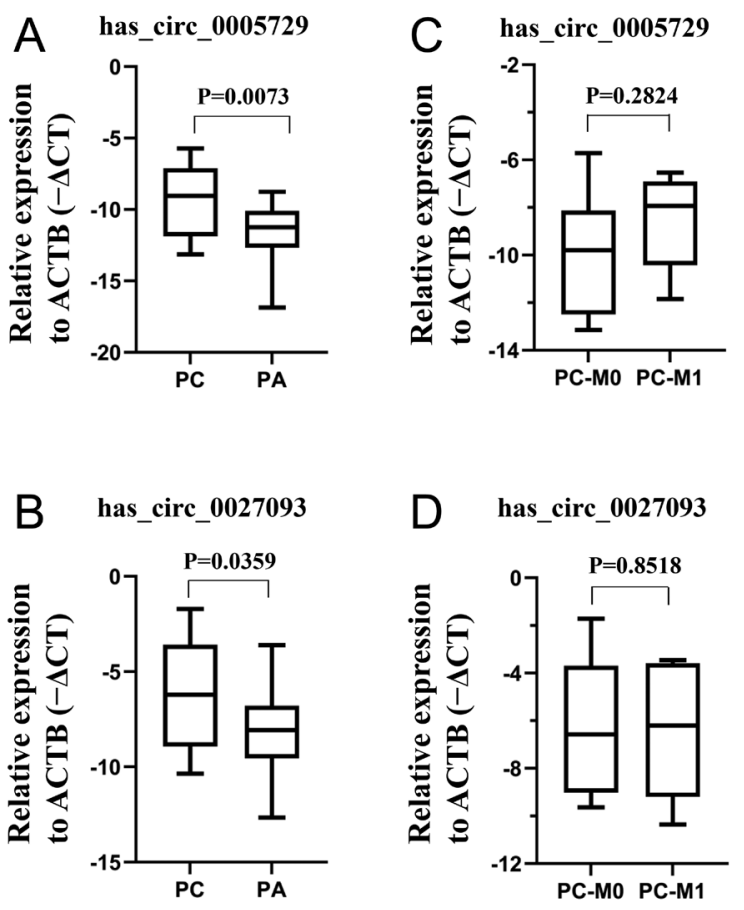
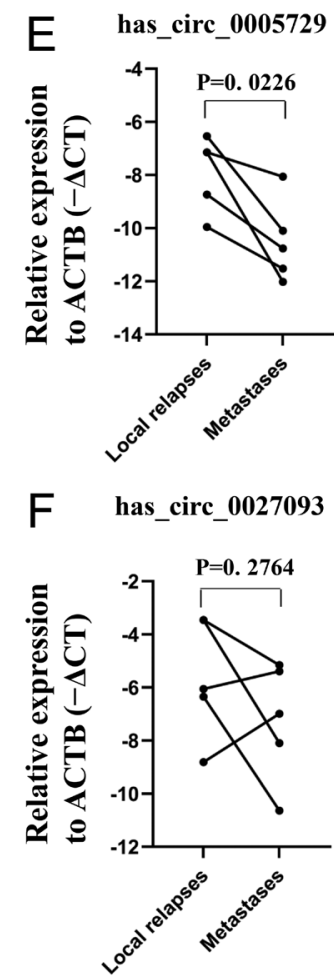

$\mathrm{F}$
Figure 2

Validation of $h s a_{-}$circ_0005729 and hsa_circ_0027093 expression in 14 PC and 40 PA tissues by qRT-PCR. (A and B) Boxplots: Hsa_circ_0005729 and hsa_circ_0027093 were verified significantly higher in PC than in the patients with PA by qRT-PCR using the $-\triangle C T$ on the $y$-axis. ( $C$ and $D$ ) Boxplots: There was no significant difference in hsa_circ_0005729 expression between patients with PC with distant metastases (PC-M1) $(n=6)$ and without distant metastases (PC-M0) $(n=8)$, as well as hsa_circ_0027093. (E) Scatter plot: Hsa_circ_0005729 expression was higher in the local relapses than in the matched distant metastases of the same patient. (F) Scatter plot: there was no significant difference in hsa_circ_0027093 expression between the local relapses and the matched distant metastases. hsa_circ_0027093 between the first-operated patients with PC and the multifold-operated PC patients, with $P=0.440$ and $P=0.659$, respectively.

\section{Several laboratory parameters were expressed higher in the 14 patients with PC than that in 40 patients with PA}

We analyzed several laboratory parameters between PC and patients with PA, and the results showed that the levels of serum calcium $(P=0.0447)$, ALP $(P=0.0481)$, and creatinine $(P=0.0358)$ were significantly higher in the 14 patients with PC than in 40 patients with PA (Fig. 3A, B and C). However, there was no significant difference in calcium on the first postoperative day $(P=0.1047)$, the decline in calcium levels $(P=0.4058)$, iPTH $(P=0.0562)$, iPTH on the first postoperative day $(P=0.0698)$, the decline in iPTH $(P=0.5913)$, phosphorus $(P=0.0745)$, 25-hydroxy vitamin $\mathrm{D}(P=0.2510), 24$-h urinary calcium $(P=0.8052)$ between the PC and patients with PA (Supplementary Fig. 1).

\section{ROC curve analysis of laboratory parameters in PC patients}

Serum calcium, creatinine, and ALP had the AUC of $0.68,0.69$ and 0.68 , respectively, while the AUC of hsa_circ_0005729 and hsa_circ_0027093 was 0.74 and 0.69, separately. The AUC was 0.86 when $h s a \_c i r c \_005729$ was combined with serum calcium, creatinine, and ALP (Fig. 3D, E, F and G), while AUC was 0.79 when $h s a \_c i r c \_0027093$ was combined with the above three indexes. The median levels and the cutoff values according to the Euclidean index of all parameters are shown in Table 3.

The correlation between $h s a_{-}$circ_0005729 and RNF138 mRNA in PA and PC patients

Hsa_circ_O005729 is translated from the RNF138 gene, and we measured RNF138 mRNA in 14 patients with PC and 40 patients with PA. The results showed no significant difference in RNF138 mRNA expression between patients with PC and patients with PA (Fig. 4A). Additionally, we analyzed the relationship between hsa_circ_0005729 and RNF138 mRNA, and the results revealed that hsa_circ_0005729 expression was positively correlated with $R N F 138$ mRNA (Pearson's $\mathrm{r}=0.375, P=0.005$ ) slightly in all 54 patients (Fig. 4B). Subgroup analysis showed a positive correlation between hsa_circ_0005729 and RNF138 mRNA in 40 patients with PA (Pearson's $r=0.468, P=0.002$ ) (Fig. 4C). However, there was no correlation between hsa_circ_0005729 and RNF138 mRNA in 14 patients with PC (Pearson's $r=0.318, P=0.268$ ) (Fig. 4D).

This work is licensed under a Creative Commons Attribution-NonCommercial-NoDerivatives 4.0 enternationab dicense.ifica . com at 04/26/2023 01:23:31AM 
A

$\mathrm{P}=0.0447$

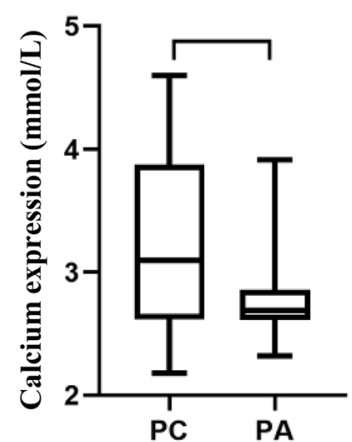

C

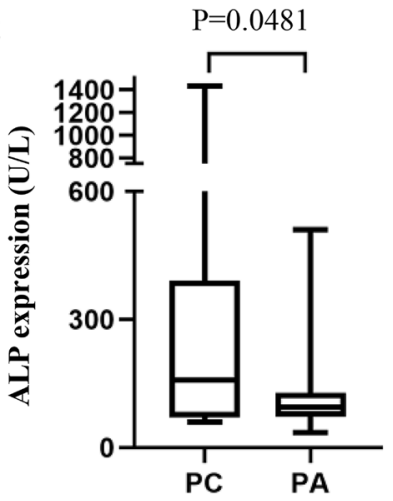

E

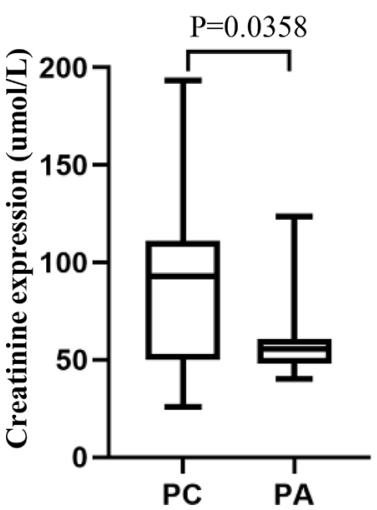

B

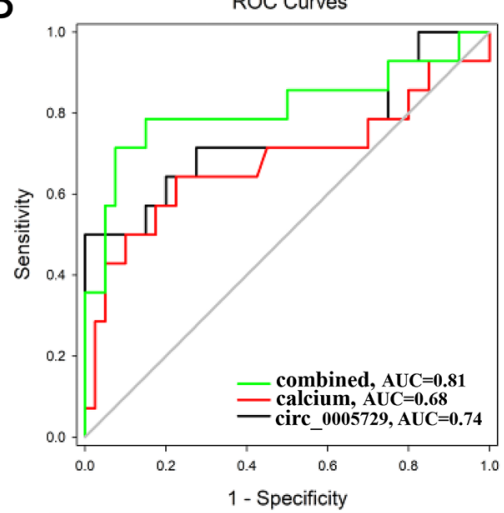

D

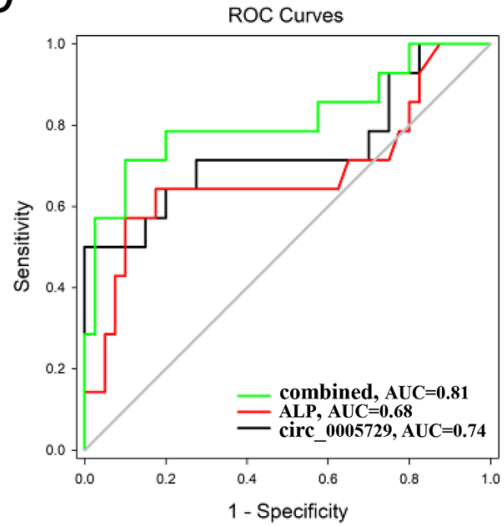

F

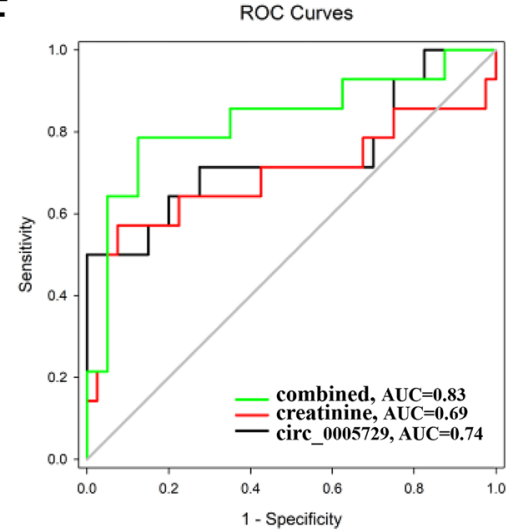

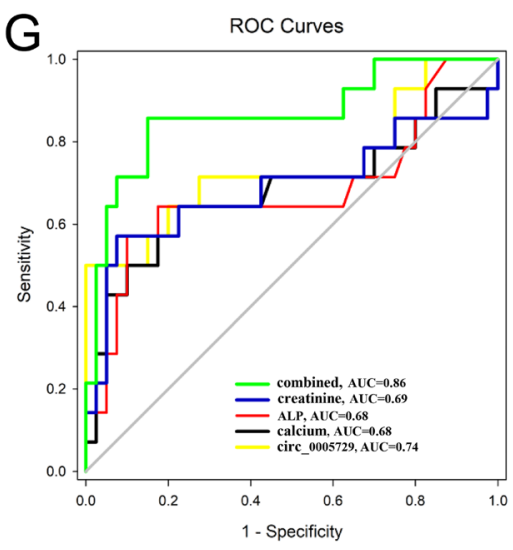

https://ec.bioscientifica.com

Figure 3

Hsa_circ_0005729 enhanced the accuracy in diagnosing PC by combination with serum calcium, alkaline phosphatase (ALP), and creatinine. (A) Boxplot: serum calcium was significantly higher in 14 patients with $P C$ than in the 40 patients with PA using the $-\triangle C T$ on the $y$-axis. (B) ROC curve: AUC was 0.81 when hsa_circ_0005729 was combined with serum calcium (AUC 0.68). (C) Boxplot: ALP was significantly higher in the 14 patients with $P C$ than in 40 patients with PA. (D) ROC curve: AUC was 0.81 when hsa_circ_0005729 was combined with ALP (AUC 0.68). (E) Boxplot: creatinine was significantly higher in 14 patients with $P C$ than in 40 patients with PA. (F) ROC curve: AUC was 0.83 when hsa_circ 0005729 was combined with creatinine (AUC 0.69). (G) ROC curve: the maximum AUC was 0.86 when hsa_circ 0005729 was combined with ALP, serum calcium, and creatinine. 
Table 3 ROC curve and AUC analysis of laboratory parameters in parathyroid carcinoma (PC).

\begin{tabular}{|c|c|c|c|c|c|c|}
\hline Parameters (reference range) & $\begin{array}{c}\text { PC } \\
\text { (median value) }\end{array}$ & $\begin{array}{c}\text { PA } \\
\text { (median value) }\end{array}$ & $\begin{array}{l}\text { Cutoff } \\
\text { value }\end{array}$ & Sensitivity $(95 \% \mathrm{Cls})$ & Specificity $(95 \% \mathrm{Cls})$ & AUC \\
\hline Hsa_circ_0005729 (- $\triangle \mathrm{CT})$ & -9.04 & -11.24 & -10.26 & $\overline{71.43 \%(0.4190-0.9161)}$ & $72.5 \%(0.5611-0.8540)$ & 0.74 \\
\hline Has_circ_0027093 $(-\Delta C T)$ & -6.20 & -8.07 & -6.36 & $57.14 \%(0.2886-0.8234)$ & $82.5 \%(0.6722-0.9266)$ & 0.69 \\
\hline $\begin{array}{l}\text { Serum calcium } \\
(2.11-2.52 \mathrm{mmol} / \mathrm{L})\end{array}$ & 3.10 & 2.69 & 2.88 & $64.29 \%(0.3514-0.8724)$ & $77.5 \%(0.6155-0.8916)$ & 0.68 \\
\hline Creatinine (41.0-81.0 $\mu \mathrm{mol} / \mathrm{L})$ & 92.90 & 55.35 & 61.25 & $64.29 \%(0.3514-0.8724)$ & $77.5 \%(0.6155-0.8916)$ & 0.69 \\
\hline ALP (45-125 U/L) & 158 & 95 & 137 & $64.29 \%(0.3514-0.8724)$ & $82.50 \%(0.6722-0.9266)$ & 0.68 \\
\hline \multirow{2}{*}{\multicolumn{6}{|c|}{$\begin{array}{l}\text { Has_circ_0027093 combined with serum calcium, creatinine, and ALP } \\
\text { Hsa_circ } 0005729 \text { combined with serum calcium, creatinine, and ALP }\end{array}$}} & 0.79 \\
\hline & & & & & & 0.86 \\
\hline
\end{tabular}

ALP, alkaline phosphatase; AUC, the area under the curve; PA, parathyroid adenoma; ROC, receiver operating characteristic.

The differences in the laboratory parameters between patients with PC with metastases and without metastases were analyzed

The laboratory parameters between patients with PC with and without metastases were analyzed. The results showed no significant difference in preoperative serum calcium $(P=0.6870)$, calcium on the first postoperative day $(P=0.3277)$, the decline in serum calcium $(P>0.9999)$, preoperative iPTH $(P=0.4136)$, the decline in iPTH $(P=0.0813)$, ALP $(P=0.9497)$, creatinine $(P=0.5728)$, phosphorus $(P=0.6870)$, and 25-hydroxyvitamin D $(P=0.2949)$ between the patients with PC with metastases and patients with PC without metastases. However, there was a significant difference in iPTH on the first postoperative day between the patients with PC with and without metastases $(P=0.020)$, which showed the level of iPTH on the first postoperative day was higher in the patients with $\mathrm{PC}$ with metastases than that in patients with PC without the metastases (Fig. 5A, B, C, D, E, F, G, H, I and $\mathrm{J}$ ). In addition, we analyzed the relationship between the hsa_circ_0005729 and iPTH on the first postoperative day, and the results showed no correlation between $h s a_{-}$ circ_0005729 and iPTH on the first postoperative day in 14 patients with PC (Pearson's $r=0.149, P=0.612$ ).

\section{Discussion}

PC is an intractable disease, and the only chance to cure it may depend on the initial en bloc resection of parathyroid lesions with ipsilateral hemithyroidectomy to achieve negative incision margins, avoid tumor rupture, and spillage $(1,4,5)$. Studies showed that the PC is insensitive
A
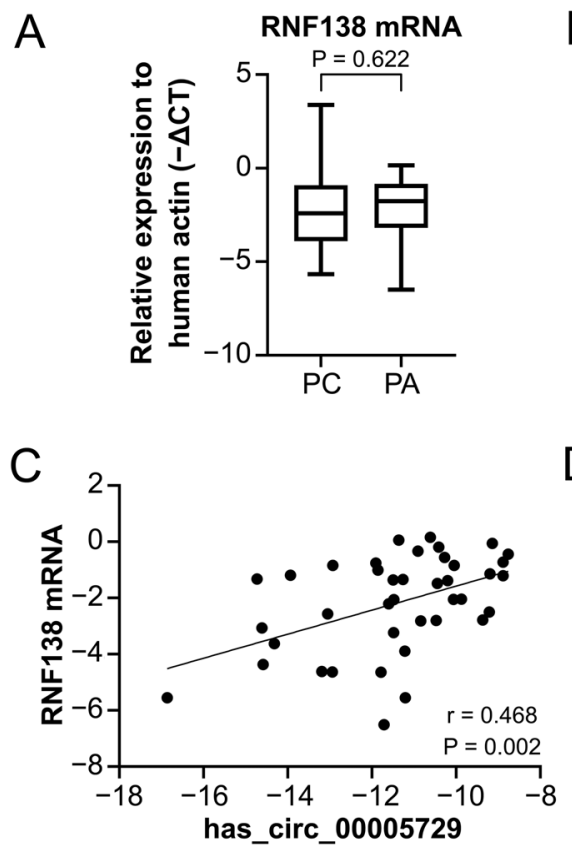

B

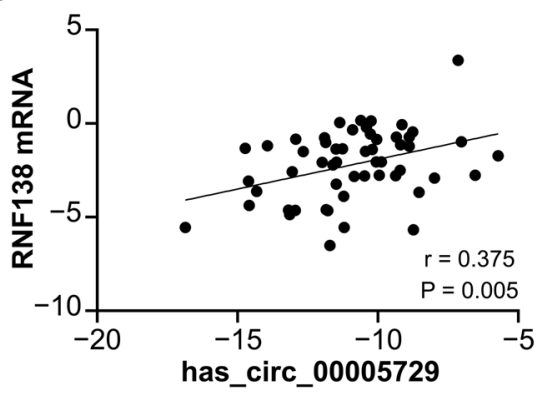

D

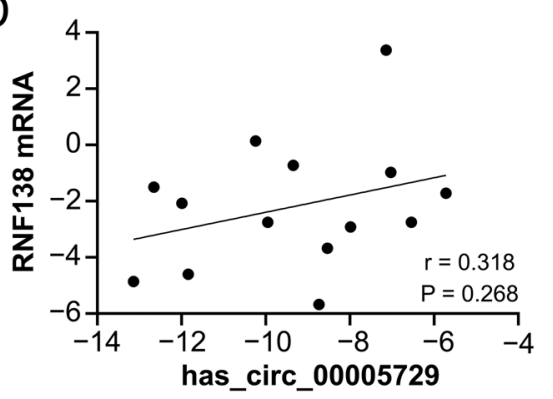

Figure 4

Hsa_circ_0005729 expression was positively correlated with RNF138 mRNA in patients with PA but not in PC patients. (A) Boxplot: RNF138 mRNA, the corresponding linear transcript of hsa_circ_0005729, was measured by qRT-PCR, and there was no significant difference in RNF138 mRNA expression between 14 patients with $P C$ and 40 patients with PA using the $-\triangle C T$ on the $y$-axis. (B) Scatter plot with trend lines: the relationship between $h s a$ circ 0005729 and RNF138 mRNA was analyzed by Pearson's correlation analysis, and hsa_circ_0005729 expression was positively correlated with RNF138 mRNA (Pearson's $r=0.375, P=0.005$ ) slightly in all 54 patients. (C) Scatter plot with trend lines: Hsa_circ_0005729 expression was positively correlated with RNF138 mRNA in 40 patients with PA (Pearson's $r=0.468, P=0.002$ ). (D) Scatter plot with trend lines: there was no significant correlation between hsa_circ_0005729 and RNF138 mRNA in 14 patients with PC (Pearson's $r=0.318, P=0.268$ ). https://ec.bioscientifica.com https://doi.org/10.1530/EC-21-0605 (c) 2022 The authors Published by Bioscientifica Ltd

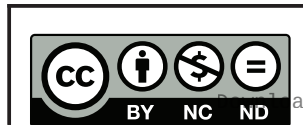

This work is licensed under a Creative Commons Attribution-NonCommercial-NoDerivatives 4.0 Internationab dicense ifica.com at 04/26/2023 01:23:31AM 
A

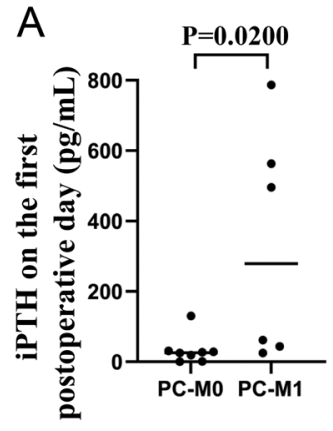

$\mathrm{F}$

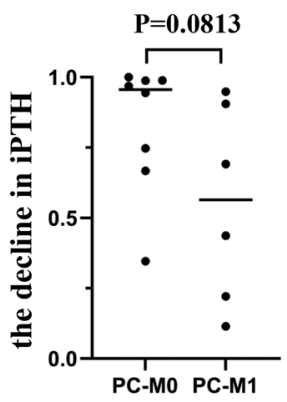

B
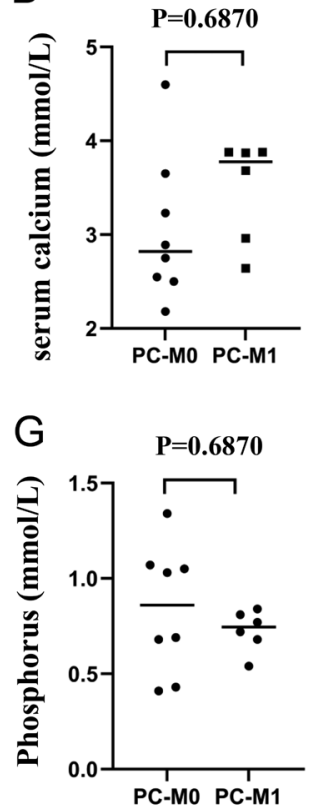
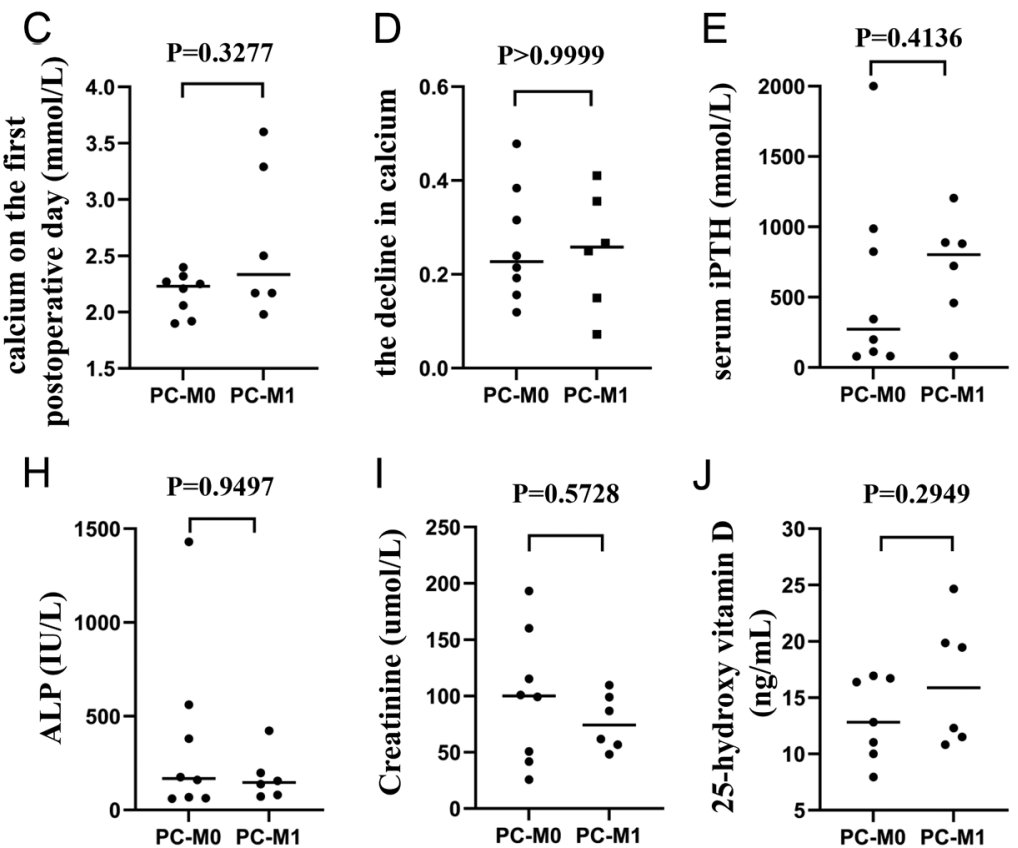

Figure 5

The differences in laboratory parameters between patients with PC with metastases and without metastases were analyzed. (A) Scatter plots: the results showed a significant difference in the iPTH on the first postoperative day between 6 patients with PC with the metastases and 8 patients with PC without metastases $(P=0.0200)$, which showed the level of $\mathrm{PPTH}$ on the first postoperative day was higher in patients with PC with the metastases than in patients with PC without metastases. ( $B, C, D, E, F, G, H, I$ and J) Scatter plots: there was no significant difference in preoperative serum calcium $(P=0.6870)$, calcium on the first postoperative day $(P=0.3277)$, the decline in serum calcium $(P>0.9999)$, preoperative iPTH $(P=0.4136)$, the decline in IPTH $(P=0.0813)$, phosphorus $(P=0.6870)$, ALP $(P=0.9497)$, creatinine $(P=0.5728), 25$-hydroxyvitamin $\mathrm{D}(P=0.2949)$ between 6 patients with PC with metastases and 8 patients with PC without the metastases.

to chemotherapy and radiotherapy in most patients with PC $(5,6,8,14)$, and chemoradiotherapy may be used when patients cannot tolerate surgery $(7,33)$. Sorafenib and Lenvatinib have been reported to be the effectively targeted drugs for patients with PC in two studies $(34,35)$.

It is of paramount importance to diagnose the PC preoperatively, which may provide a basis for performing en bloc resection. However, there is no specific method for diagnosing the PC preoperatively so far. In this study, a novel circular RNA hsa_circ_0005729 was found significantly higher in the PC than in patients with PA, and hsa_circ_0005729 had the biggest AUC than any other biochemical indices such as serum calcium, ALP, and creatinine.

Most studies have shown that PC mainly occurs in the fifth decade of life (36), and the mean age of the patients with PC in our cohort was 42.9 years, consistent with a study including the 70 patients with PC who had a mean age of 44.3 years (37). Other studies showed older ages for the occurrence of the PC, such as 58.0 years in a survey including the 21 patients with PC (36) and 56.9 years in another study with $>1022$ patients with PC (14). The age at diagnosis of PC is approximately 10 years earlier than that of the PA $(14,36)$, this was confirmed in our studies, which showed that the mean age of patients with PC was 42.9 years at the time of the initial operation, approximately 7 years earlier than the mean age of patients with PA (49.4 years). In addition, most studies have shown that there is no sex predominance in the patients with PC, while patients with PA tend to be female of 3-4 times than the males (1, $9,10,15)$. These results are consistent with our results, which showed no male-female difference among the 14 PC patients, but a female-to-male ratio of 2.3:1 among the 40 patients with PA. However, one study showed PC cases had male predominance with seven males and four females (38).

To identify an effective biomarker distinguishing PC from PA, a novel circular RNA hsa_circ_0005729 expression was verified higher in PC patients, and the levels of preoperative serum calcium, ALP, and creatinine were also higher in PC than in the patients with PA. We calculated the AUC of each index and found the AUC of hsa_circ_0005729 was bigger than any index alone; the AUC increased to 0.86 when hsa_circ_0005729 was combined with serum calcium, ALP, and creatinine, with the cutoff value of $2.88 \mathrm{mmol} / \mathrm{L}, 137 \mathrm{IU} / \mathrm{L}$, and $61.25 \mu \mathrm{mol} / \mathrm{L}$, respectively.

This work is licensed under a Creative Commons Attribution-NonCommercial-NoDerivatives 4.0 international dicense.ifica. com at 04/26/2023 01:23:31AM 
Our results were consistent with some findings of another study, which showed that the expression of serum calcium and ALP was significantly higher in PC than in patients with PA. However, they showed significant differences in iPTH between PC and patients with PA and revealed that ALP combined with tumor size could differentiate PC from PA with a cutoff value of $285 \mathrm{IU} / \mathrm{L}$, and a tumor size $>3.0 \mathrm{~cm}$ (38). Serum iPTH, a specific biomarker for hyperparathyroidism, being often higher in patients with PC than in patients with PA, was found to have no significant differences between patients with PC and patients with PA in this study. These differences may be due to the small number of PC cases enrolled in both the studies, with 14 PC cases in this study and 11 PC cases in another study. In addition, $86 \%$ of the patients with PC in this study were local relapses with multiple cervical lesions, which could not be accounted for in terms of tumor size; even six patients with PC had distant metastases.

However, our results revealed that the level of iPTH on the first postoperative day was higher in the six patients with PC with metastases than in the eight patients with PC without metastases. Up to now, there are no studies on molecules in the distant metastases of PC. This study collected four local cervical relapses, four matched lung metastases, and one matched liver metastases. We analyzed the hsa_circ_0005729 expression between the cervical relapses and distant metastases of the same patients. The results showed that the hsa_circ_0005729 expression level was higher in local relapses than in matched distant metastases. However, the underlying mechanisms were not studied.

RNF138 gene encodes $h s a \_c i r c \_0005729$. Recent studies revealed that $R N F 138$ is an essential factor in maintaining chromosome integrity (39), and RNF138 mRNA is expressed at significantly higher levels in glioma tissues than in adjacent non-cancerous brain tissues (40). We measured RNF138 mRNA expression in tissue samples of $14 \mathrm{PC}$ and 40 patients with PA; however, we found no significant difference in RNF138 mRNA expression between patients with PC and patients with PA. In addition, correlation analysis revealed that hsa_circ_0005729 and RNF138 mRNA were not correlated in the 14 patients with PC but positively associated in the $40 \mathrm{PA}$ cases, indicating that the mechanisms underlying PC and PA are different. Costa Guda et al. reported that the deletion of chromosome 11q allele is the most common change in PA, but it has never been detected in PC, suggesting that the latter arises de novo rather than evolving from pre-existing benign parathyroid diseases (41).
This study has limitations. First, only 14 patients with PC were enrolled in this study. Secondly, the results showed that hsa_circ_0005729 expression was higher in the PC than in PA, higher in local relapses than in the matched distant metastases, and $h s a_{\text {_circ_O005729 }}$ was positively correlated with RNF138 mRNA in patients with PA but not in the PC patients. However, the mechanisms have not been studied.

\section{Conclusions}

In summary, this was one of the few studies that revealed the circular RNAs in patients with PC. A novel circular RNA hsa_circ_0005729 may be a promising biomarker for distinguishing the PC from PA. In addition, this is the first study to measure the circular RNAs in matched distant metastases of patients with PC. More patients with PC need to be studied to unveil the underlying mechanisms of the PC gradually in future work.

\section{Supplementary materials}

This is linked to the online version of the paper at https://doi.org/10.1530/ EC-21-0605.

\section{Declaration of interest}

The authors declare that there is no conflict of interest that could be perceived as prejudicing the impartiality of the research reported.

\section{Funding}

This work was supported by the Beijing Chaoyang Hospital, Capital Medical University (No. CYYPY201808), and Capital Medical University (No. 1200020122).

\section{Availability of data and materials}

The datasets are available from the corresponding author upon reasonable request.

\section{Author contribution statement}

Bojun Wei and Qian Wang were responsible for the study concept and design, and Qian Wang performed all experiments and wrote the manuscript. Jiacheng Wang, Yunhui Xin, and Ziyang He collected the data and analyzed. Xiang Zhou and Mulan jin were responsible for the pathological diagnoses of PC. Xing Liu, Teng Zhao and Hong Shen assisted in tissue sample collection.

\section{Acknowledgement}

This work was supported by the Department of Thyroid and Neck Surgery, Beijing Chaoyang Hospital, Capital Medical University. (c) 2022 The authors Published by Bioscientifica Ltd
This work is licensed under a Creative Commons Attribution-NonCommercial-NoDerivatives 4.0 International License ifica com at $04 / 26 / 2023 \quad 01: 23: 314 M$ 


\section{References}

1 Hundahl SA, Fleming ID, Fremgen AM \& Menck HR. Two hundred eighty-six cases of parathyroid carcinoma treated in the U.S. between 1985-1995: a National Cancer Data Base Report. The American College of Surgeons Commission on Cancer and the American Cancer Society. Cancer 199986 538-544. (https://doi.org/10.1002/(sici)10970142(19990801)86:3<538::aid-cncr25>3.0.co;2-k)

2 Wang $\mathrm{O}$, Wang C, Nie M, Cui Q, Guan H, Jiang Y, Li M, Xia W, Meng X \& Xing X. Novel HRPT2/CDC73 gene mutations and loss of expression of parafibromin in Chinese patients with clinically sporadic parathyroid carcinomas. PLoS ONE 20127 e45567. (https:// doi.org/10.1371/journal.pone.0045567)

3 Koea JB \& Shaw JH. Parathyroid cancer: biology and management. Surgical Oncology 19998 155-165. (https://doi.org/10.1016/s09607404(99)00037-7)

4 Wilhelm SM, Wang TS, Ruan DT, Lee JA, Asa SL, Duh QY, Doherty GM, Herrera MF, Pasieka JL, Perrier ND, et al. The American Association of Endocrine Surgeons Guidelines for definitive management of primary hyperparathyroidism. JAMA Surgery 2016151 959-968. (https://doi. org/10.1001/jamasurg.2016.2310)

5 Busaidy NL, Jimenez C, Habra MA, Schultz PN, El-Naggar AK \& Clayman GL, Asper JA, Diaz EM, Evans DB, Gagel RF. Parathyroid carcinoma: a 22-year experience. Head and Neck 200426 716-726. (https://doi.org/10.1002/hed.20049)

6 Christakis I, Silva AM, Kwatampora LJ, Warneke CL, Clarke CN \& Williams MD. Oncologic progress for the treatment of parathyroid carcinoma is needed. Journal of Surgical Oncology 2016114 708-713. (https://doi.org/10.1002/jso.24407)

7 Wynne AG, van Heerden J, Carney JA \& Fitzpatrick LA. Parathyroid carcinoma: clinical and pathologic features in 43 patients. Medicine 199271 197-205. (https://doi.org/10.1097/00005792-199207000-00002)

8 Goswamy J, Lei M \& Simo R. Parathyroid carcinoma. Current Opinion in Otolaryngology and Head and Neck Surgery 201624 155-162. (https:// doi.org/10.1097/MOO.0000000000000234)

9 van der Zwan JM, Mallone S, van Dijk B, Bielska-Lasota M, Otter R \& Foschi R, Baudin E, Links TP \& RARECARE WG. Carcinoma of endocrine organs: results of the RARECARE project. European Journal of Cancer 201248 1923-1931. (https://doi.org/10.1016/j. ejca.2012.01.029)

10 Lee PK, Jarosek SL, Virnig BA, Evasovich M \& Tuttle TM. Trends in the incidence and treatment of parathyroid cancer in the United States. Cancer 2007109 1736-1741. (https://doi.org/10.1002/cncr.22599)

11 Sandelin K, Auer G, Bondeson L, Grimelius L \& Farnebo LO. Prognostic factors in parathyroid cancer: a review of 95 cases. World Journal of Surgery 199216 724-731. (https://doi.org/10.1007/ BF02067369)

12 Ryhänen EM, Leijon H, Metso S, Eloranta E, Korsoff P, Ahtiainen P, Kekäläinen P, Tamminen M, Ristamäki R, Knutar O, et al. A nationwide study on parathyroid carcinoma. Acta Oncologica 201756 991-1003. (https://doi.org/10.1080/0284186X.2017.1306103)

13 Rodrigo JP, Hernandez-Prera JC, Randolph GW, Zafereo ME, Hartl DM \& Silver CE. Parathyroid cancer: an update. Cancer Treatment Reviews 202086 102012. (https://doi.org/10.1016/j.ctrv.2020.102012)

14 Sadler C, Gow KW, Beierle EA, Doski JJ, Langer M \& Nuchtern JG. Parathyroid carcinoma in more than 1,000 patients: a populationlevel analysis. Surgery 2014156 1622-1630. (https://doi.org/10.1016/j. surg.2014.08.069)

15 Shaha AR \& Shah JP. Parathyroid carcinoma: a diagnostic and therapeutic challenge. Cancer 199986 378-380. (https://doi.org/10.1002/ (SICI)1097-0142(19990801)86:3<378::AID-CNCR3>3.0.CO;2-F)

16 Wei CH \& Harari A. Parathyroid carcinoma: update and guidelines for management. Current Treatment Options in Oncology 201213 11-23. (https://doi.org/10.1007/s11864-011-0171-3)
17 Al-Sobhi S, Ashari LH \& Ingemansson S. Detection of metastatic parathyroid carcinoma with Tc-99m sestamibi imaging. Clinical Nuclear Medicine 199924 21-23. (https://doi.org/10.1097/00003072199901000-00005)

18 DeLellis RA. Parathyroid carcinoma: an overview. Advances in Anatomic Pathology 200512 53-61. (https://doi.org/10.1097/01. pap.0000151319.42376.d4)

19 Erickson LA \& Mete O. Immunohistochemistry in diagnostic parathyroid pathology. Endocrine Pathology 201829 113-129. (https:// doi.org/10.1007/s12022-018-9527-6)

20 Hu Y, Zhang X, Wang O, Bi Y, Xing X, Cui M, Wang M, Tao W, Liao Q $\&$ Zhao Y. The genomic profile of parathyroid carcinoma based on whole-genome sequencing. International Journal of Cancer 2020147 2446-2457. (https://doi.org/10.1002/ijc.33166)

21 Shattuck TM, Välimäki S, Obara T, Gaz RD, Clark OH \& Shoback D, Wierman ME, Tojo K, Robbins CM, Carpten JD. Somatic and germ-line mutations of the HRPT2 gene in sporadic parathyroid carcinoma. New England Journal of Medicine 2003349 1722-1729. (https://doi. org/10.1056/NEJMoa031237)

22 Cetani F, Banti C, Pardi E, Borsari S, Viacava P, Miccoli P, Torregrossa L, Basolo F, Pelizzo MR, Rugge M, et al. CDC73 mutational status and loss of parafibromin in the outcome of parathyroid cancer. Endocrine Connections 20132 186-195. (https://doi.org/10.1530/EC-13-0046)

23 Corbetta S, Vaira V, Guarnieri V, Scillitani A, Eller-Vainicher C, Ferrero S, Vicentini L, Chiodini I, Bisceglia M, Beck-Peccoz P, et al. Differential expression of microRNAs in human parathyroid carcinomas compared with normal parathyroid tissue. EndocrineRelated Cancer 201017 135-146. (https://doi.org/10.1677/ERC-09-0134)

24 Kristensen LS, Andersen MS, Stagsted LVW, Ebbesen KK, Hansen TB \& Kjems J. The biogenesis, biology and characterization of circular RNAs. Nature Reviews: Genetics 201920 675-691. (https://doi.org/10.1038/ s41576-019-0158-7)

25 Weng W, Wei Q, Toden S, Yoshida K, Nagasaka T, Fujiwara T, Cai S, Qin H, Ma Y \& Goel A. Circular RNA ciRS-7-A promising prognostic biomarker and a potential therapeutic target in colorectal cancer. Clinical Cancer Research 201723 3918-3928. (https://doi. org/10.1158/1078-0432.CCR-16-2541)

26 Smid M, Wilting SM, Uhr K, Rodríguez-González FG, de Weerd V, Prager-Van der Smissen WJC, van der Vlugt-Daane M, van Galen A, Nik-Zainal S, Butler A, et al. The circular RNome of primary breast cancer. Genome Research 201929 356-366. (https://doi.org/10.1101/ gr.238121.118)

27 Hu Y, Zhang X, Cui M, Wang M, Su Z, Liao Q \& Zhao Y. Circular RNA profile of parathyroid neoplasms: analysis of co-expression networks of circular RNAs and mRNAs. RNA Biology 201916 1228-1236. (https:// doi.org/10.1080/15476286.2019.1622962)

28 Wei B, Zhao T, Shen H, Jin M, Zhou Q, Liu X, Wang J \& Wang Q. Extended en bloc reoperation for recurrent or persistent parathyroid carcinoma: analysis of 31 cases in a single institute experience. Annals of Surgical Oncology 202229 1208-1215. (https://doi.org/10.1245/ s10434-021-10962-7)

29 Lloyd RV. WHO Classification of Tumours of Endocrine Organs, 4th ed. Lyon, France: IARC.

30 DeLong ER, DeLong DM \& Clarke-Pearson DL. Comparing the areas under two or more correlated receiver operating characteristic curves: a nonparametric approach. Biometrics 198844 837-845. (https://doi. org/10.2307/2531595)

31 Hajian-Tilaki K. The choice of methods in determining the optimal cut-off value for quantitative diagnostic test evaluation. Statistical Methods in Medical Research 201827 2374-2383. (https://doi. org/10.1177/0962280216680383)

32 Schulte KM, Gill AJ, Barczynski M, Karakas E, Miyauchi A, Knoefel WT, Lombardi CP, Talat N, Diaz-Cano S \& Grant CS. Classification of parathyroid cancer. Annals of Surgical Oncology 201219 2620-2628. (https://doi.org/10.1245/s10434-012-2306-6) https://ec.bioscientifica.com https://doi.org/10.1530/EC-21-0605
(C) 2022 The authors Published by Bioscientifica Ltd

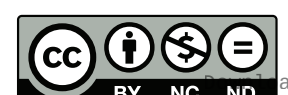

This work is licensed under a Creative Commons Attribution-NonCommercial-NoDerivatives 4.0 elnternationab ficense.ifica com at 04/26/2023 01:23:31AM 
33 Vellanki P, Lange K, Elaraj D, Kopp PA \& El Muayed M. Denosumab for management of parathyroid carcinoma-mediated hypercalcemia. Journal of Clinical Endocrinology and Metabolism 201499 387-390. (https://doi.org/10.1210/jc.2013-3031)

34 Akirov A, Asa SL, Larouche V, Mete O, Sawka AM \& Jang R. The clinicopathological spectrum of parathyroid carcinoma. Frontiers in Endocrinology 201910 731. (https://doi.org/10.3389/fendo.2019.00731)

35 Kutahyalioglu M, Nguyen HT, Kwatampora L, Clarke C, Silva A, Ibrahim E, Waguespack SG, Cabanillas ME, Jimenez C, Hu MI, et al. Genetic profiling as a clinical tool in advanced parathyroid carcinoma. Journal of Cancer Research and Clinical Oncology 2019145 1977-1986. (https://doi.org/10.1007/s00432-019-02945-9)

36 Quaglino F, Manfrino L, Cestino L, Giusti M, Mazza E, Piovesan A, Palestini N, Lauro C \& Castellano E. Parathyroid carcinoma: an up-to-date retrospective multicentric analysis. International Journal of Endocrinology 20202020 7048185. (https://doi.org/10.1155/2020/7048185)

37 Schantz A \& Castleman B. Parathyroid carcinoma. A study of 70 cases. Cancer 197331 600-605. (https://doi.org/10.1002/10970142(197303)31:3<600::aid-cncr2820310316>3.0.co;2-0)
38 Bae JH, Choi HJ, Lee Y, Moon MK, Park YJ, Shin CS, Park DJ, Jang HC, Kim SY \& Kim SW. Preoperative predictive factors for parathyroid carcinoma in patients with primary hyperparathyroidism. Journal of Korean Medical Science 201227 890-895. (https://doi.org/10.3346/ jkms.2012.27.8.890)

39 Yard BD, Reilly NM, Bedenbaugh MK \& Pittman DL. RNF138 interacts with RAD51D and is required for DNA interstrand crosslink repair and maintaining chromosome integrity. DNA Repair 201642 82-93. (https://doi.org/10.1016/j.dnarep.2016.04.006)

40 Zhou YX, Chen SS, Wu TF, Ding DD, Chen XH, Chen JM, Su ZP, Li B, Chen GL, Xie XS, et al. A novel gene RNF138 expressed in human gliomas and its function in the glioma cell line U251. Analytical Cellular Pathology 201235 167-178. (https://doi.org/10.3233/ACP2011-0051)

41 Costa-Guda J, Imanishi Y, Palanisamy N, Kawamata N, Phillip Koeffler H, Chaganti RS \& Arnold A. Allelic imbalance in sporadic parathyroid carcinoma and evidence for its de novo origins. Endocrine 201344 489-495. (https://doi.org/10.1007/s12020-0139903-4)

Received in final form 4 January 2022

Accepted 14 January 2022

Accepted Manuscript published online 14 January 2022 (c) 2022 The authors Published by Bioscientifica Ltd
This work is licensed under a Creative Commons Attribution-NonCommercial-NoDerivatives 4.0

Internationab ficense.ifica . com at 04/26/2023 01:23:31AM 